\title{
Follow-up to the baby friendly hospital initiative in two hospitals of the Mexican Social Security Institute
}

\author{
Marianne G. Monroy-Azuaraํ, Graciela S. Arciga-Vázquez¹, Elba N. Cano-Vázquez², \\ Socorro Méndez-Martínez ${ }^{3 *}$, Guillermo Islas-Hernández ${ }^{4}$, Ma. Sabina Rodríguez-Ramírez ${ }^{5}$, \\ Dulcina Vargas-Ramírez ${ }^{6}$ y Rubí Z. Arroyo-García ${ }^{7}$
}

${ }^{1}$ Medical Department, Universidad Popular Autónoma del Estado de Puebla; ${ }^{2}$ Medical Department, Universidad de las Américas; ${ }^{3}$ Planning Coordination and Institutional Liaison in Health, State Delegation, Instituto Mexicano del Seguro Social; ${ }^{4}$ Coordination in Prevention and Health Attention, Instituto Mexicano del Seguro Social; ${ }^{5}$ Supervisory nursing of Public Health, State Delegation, Instituto Mexicano del Seguro Social; ${ }^{6}$ Social work supervision, State Delegation, Instituto Mexicano del Seguro Social; ${ }^{7}$ Family Medicine Unit \#2, State Delegation, Instituto Mexicano del Seguro Social. Puebla, Mexico

\section{Abstract}

Background: The Baby Friendly Hospital Initiative has proven to be effective to increase exclusive and prolonged breastfeeding. Material and methods: Longitudinal study, in two hospitals of second level, in the period from 2015 to 2018. A percentage above $85 \%$ in each step was considered acceptable. The statistical analysis was descriptive using student's test to compare the mean between the two hospitals and ANOVA to compare the mean throughout time in SPSS v.25. Results: Steps 1 and 7 were different between the hospitals with $p=0.010$ and $p=0.023$, respectively. In the follow-up, General Zone Hospital No. 5 kept steps 1, 2, 3, 7,8, and 9 above 85\%, while those who did not were steps 4, 5, 6, and 10, $p=0.37$. Steps of General Hospital No. 15 that remained over $85 \%$ were 1, 3, 7, and 9; those that oscillated over time with a $<85 \%$ rating were steps 2, 4, 5, 6, 8, and 10, $p=0.003$. Conclusion: Monitoring child-friendly hospitals allow us to observe areas of opportunity to strengthen training for both clinical and non-clinical staff, pregnant women, the general population, and to improve exclusive and prolonged breastfeeding.

Key words: Breastfeeding. 10 steps. Infant feeding.

\section{Seguimiento de la iniciativa hospital amigo del niño y la niña en dos hospitales del Instituto Mexicano del Seguro Social}

\section{Resumen}

Introducción: La Iniciativa Hospital Amigo del Niño y la Niña ha probado ser efectiva para mejorar la lactancia materna exclusiva y prolongada. Material y métodos: Estudio longitudinal, en dos hospitales de segundo nivel, en el periodo de 2015 a 2018. Un porcentaje superior al 85\% en cada paso se consideró aceptable. El análisis estadístico fue descriptivo, utilizando la prueba t de Student para comparar las medias entre los dos hospitales y el análisis de la varianza para compararlas a lo largo del tiempo empleando el programa SPSS v.25. Resultados: Los pasos 1 y 7 variaron entre los hospitales (con $p$ $=0.010$ y $p=0.023$, respectivamente). En el seguimiento, el Hospital General de Zona (HGZ) 5 mantuvo los pasos 1, 2, 3, 7, 8 y 9 por encima del 85\%, y< 85\% los pasos 4, 5, 6 y 10 ( $p=0.37)$. Las medidas del HGZ 15 que se mantuvieron > 85\% fueron 1, 3, 7 y 9; aquellos que oscilaron a lo largo del tiempo con una calificación < 85\% fueron los pasos 2, 4, 5, 6, 8 y 10 ( $p=0.003)$. Conclusión: Estos seguimientos permiten observar áreas de oportunidad para reforzar la capacitación al personal clínico y no clínico como a las mujeres embarazadas, a la población en general y para mejorar la lactancia materna exclusiva y prolongada.

Palabras clave: Lactancia materna. 10 pasos. Alimentación infantil.

\section{Correspondence:}

Socorro Méndez-Martínez

E-mail: socorro.mendez@imss.gob.mx

Available online: 28-12-2021

Date of reception: 10-12-2019 Date of acceptance: 16-08-2021 DOI: 10.24875/PER.19000085
Perinatol Reprod Hum. 2021;35(1):17-22

www.perinatologia.mx CC BY-NC-ND license (http://creativecommons.org/licenses/by-nc-nd/4.0/) 


\section{Introduction}

The Baby Friendly Hospital Initiative was originally launched in 1991, designed by the World Health Organization (WHO) and the United Nations International Children's Emergency Fund (UNICEF) ${ }^{1}$, with the aim of improving the initiation, duration and exclusivity of breastfeeding and implementing them as an indispensable activity in hospital units. It consists of the training of a multidisciplinary team focused on the acquisition of skills necessary for clinical practice and effective management of the promotion, protection and support of breastfeeding ${ }^{2}$. To receive the nomination or renomination as a Baby Friendly Hospital the units are evaluated by a group of expert advisors who are trained health professionals in a 40-h course, accredited as evaluators who verify compliance with the 10 steps $^{3}$ and 3 annexes such as the International Code of Marketing of Breast milk substitutes restricting the use of breast milk substitutes, annex 2 on friendly care during childbirth and annex 3 on human immunodeficiency virus and infant feeding.

One of the Global Goals of the WHO is to increase the percentage of exclusive breastfeeding from $37 \%$ in 2012 to $50 \%$ by $2025^{4}$. Since its launch, the Baby Friendly Hospital Initiative has been disseminated globally and has reached more than 152 countries, nominating more than 20,000 institutions ${ }^{4}$ representing $27.5 \%$ of all maternity institutions in the world; approximately $8.5 \%$ in industrialized countries and $31 \%$ in less developed countries ${ }^{5}$.

The WHO recommends initiation of breastfeeding within the $1^{\text {st }} \mathrm{h}$ after birth, exclusive breastfeeding for the first 6 months of life, followed by complementary breastfeeding until age 2 or more ${ }^{6}$.

Several studies indicate that the Baby Friendly Hospital Initiative has a positive long-term impact on women's health, nutrition, physical, and mental health ${ }^{7}$ and should also be considered as a right for the mother-child binomial ${ }^{8}$.

There is evidence of the follow-up to Baby Friendly hospitals, with the purpose of evaluating implementation, as well as identifying the steps that are most difficult to implement and in proposing solutions.

The implementation of the Baby Friendly Initiative has faced multiple obstacles due to factors such as the customs of the country, the culture they practice, and among others. In Brazil, this initiative has been around 25 years and in line with the ten steps in the country, it must comply with Brazil's specific laws on breastfeeding $^{2}$. The evaluation of nominated hospitals in Brazil reported that the steps with difficulties in their implementation were 6,7 , and 9 with $80 \%$ steps 3 and 5 with $70 \%$ and steps $1,4,8$, and 10 with $<50 \%$.

The Baby Friendly Hospital Initiativehas been followed up in different countries, some of them are: Brazil $^{2}$, United States ${ }^{9-11}$, and Pakistan ${ }^{12,13}$. The evaluation of the percentage of each step (shown in Table 1) is considered approved if it is $\geq 85 \%$ and we found that the average of none of the steps reached this percentage.

\section{Materials and methods}

It is a descriptive study evaluating the compliance of the two certified hospitals in the state of Puebla with Baby Friendly Initiative.

\section{Measurements}

To maintain the nomination and re-nomination, the staff of the Delegation in Puebla, monitors and evaluates the Baby Friendly program every 6 months. In this study, the evaluations were recorded from February 2015 to June 2018, to 2 hospital centers. This data were recorded and emptied in a database. This study used a hospital monitoring and self-assessment tool from the $\mathrm{WHO}^{14}$.

The tool explores the following domains: a questionnaire to the mother focused on her experience in prenatal care, information given regarding the benefits of breastfeeding and a detailed explanation of the events that will occur during her labor, and the practices that were performed in the postpartum period regarding breastfeeding.

As part of the tool an evaluation is carried out by the director of the hospital unit, which breaks down step by step all the parameters that must be met for the hospital to maintain its nomination as Baby Friendly Hospital. The hospital must obtain a minimum of $85 \%$ as an overall global grade.

\section{Data collection}

The data collection was based on a survey created by the WHO, designed to evaluate in detail the follow-up to the 10-step program. The data were gathered from two hospitals nominated as Baby Friendly in the state of Puebla during the period from 2015 to 2019. These evaluations are carried out every 6 months after the unit is nominated. 
Table 1. Comparison between follow-up of the 10 steps in different Baby Friendly Hospitals and the study described, expressed as a percentage

\begin{tabular}{|c|c|c|c|c|c|c|c|c|c|c|c|}
\hline Author & Country & Step 1 & Step 2 & Step 3 & Step 4 & Step 5 & Step 6 & Step 7 & Step 8 & Step 9 & Step10 \\
\hline $\mathrm{Sda}^{2}$ & Brazil-2013 & 0 & 64.4 & 20 & 93.3 & 83.3 & 86.6 & 100 & 83.3 & 100 & 66.6 \\
\hline Taylor ${ }^{10}$ & $\begin{array}{l}\text { United } \\
\text { States }\end{array}$ & 67 & 66 & 80 & 53 & 85 & 48 & 61 & 84 & 52 & 62 \\
\hline Masood $^{12}$ & $\begin{array}{l}\text { Pakistan } \\
2016\end{array}$ & 63.5 & 67.6 & 35.1 & 12.8 & 44.6 & 29.1 & 94.6 & 85.8 & 97.3 & 92.6 \\
\hline Haiek $^{13}$ & Canada & 92 & 83 & 38 & 75 & 51 & 50 & 38 & 56 & 100 & 77 \\
\hline Hawke ${ }^{11}$ & $\begin{array}{l}\text { United } \\
\text { States, } \\
2012\end{array}$ & 14 & 59 & 19 & 91 & 74 & 90 & 79 & 98 & 60 & 73 \\
\hline Lillehoj $^{9}$ & $\begin{array}{l}\text { United } \\
\text { States }\end{array}$ & 83 & 28.3 & 22.6 & 22.6 & 58.5 & 26.4 & 15.1 & 83 & 15.1 & 22.6 \\
\hline Agbozo $^{15}$ & Ghana & 0 & 7.3 & 67 & 30.9 & 37.5 & 73 & 84.2 & 65.2 & 100 & 75 \\
\hline $\begin{array}{l}\text { General Zone } \\
\text { Hospital No. } 15\end{array}$ & $\begin{array}{l}\text { Mexico, } \\
2018\end{array}$ & 87.29 & 73.81 & 88.39 & 77.07 & 82.53 & 83.3 & 99.51 & 84.92 & 95.47 & 75.1 \\
\hline $\begin{array}{l}\text { General Zone } \\
\text { Hospital No. } 5\end{array}$ & $\begin{array}{l}\text { Mexico, } \\
2018\end{array}$ & 100 & 100 & 93.15 & 78.13 & 81.83 & 78.05 & 95.45 & 88.96 & 98.2 & 74.52 \\
\hline
\end{tabular}

\section{Ethical considerations}

Data from previous evaluations recorded in the Delegation's databases were used. For this investigation, the local health research committee authorized this research protocol with registration number R-20192106. We included two accredited hospitals where follow-up evaluations and evaluations were performed during the nomination and re-nomination of each hospital.

\section{Data analysis}

For the analysis, we used the compliance of each step for a successful breastfeeding, which were registered as a summarized inform of each hospital. In addition, the scores were compared for each step between the two hospitals.

The results of the evaluation analysis were described by compliance levels, expressed as percentages for each step, in addition to the overall and one-factor ANOVA was used to compare the averages of each step over time (4 measurements for General Hospital No.5, 7 measurements for General Hospital No. 15) in SPSS v.25 (SPSS Inc. Chicago, IL, USA) and to compare the overall mean of each step we used student's t test.

\section{Results}

In the Delegation, there are 4 General Zone Hospitals and one sub-zone hospital, currently only $40 \%$ are reinforced with the Baby Friendly Hospital Initiative. From the general hospitals of zone No. 5 and 15, we obtained a total of 4 and 7 follow-up evaluations of the 10 steps, respectively. 120 women were interviewed in hospital 5 and 210 women in hospital 15, divided into groups of 30 during each follow-up to hospital units every 6 months.

The averages of the steps were analyzed individually and it was found that in hospital 5 the steps that remained over $85 \%$ were steps $1,2,3,7,8$, and 9 while the ones that went down were steps $4,5,6$, and 10 . The results of hospital 15 that remained above $85 \%$ were steps $1,3,7$, and 9 ; the ones that lowered their average were steps $2,4,5,6,8$, and 10 .

Of the 11 follow-ups, it was found that the lowest level of compliance was in the immediate attachment of the newborn to its mother with $81 \%$ non-compliance; encouraging mothers to go to support groups, which corresponds to step 10 , resulted in $72 \%$ non-compliance, and finally training for clinical staff and breastfeeding on demand with $54 \%$ non-compliance.

In the results shown in table 2, we can see that the only steps that were registered with a significant 
difference in trend over time were steps 1 and 7 with a $p=0.010$ and $p=0.023$, respectively.

We obtained the average of all follow-ups in both hospitals and found that for step 1 (the existence of a breastfeeding-focused policy) achieved an average of $91.91 \%$; step 2 (staff training) an average of $83.34 \%$; step 3 (informing mothers of the benefits of breastfeeding) an average of $90.12 \%$; step 4 (skin-to-skin contact) an average of $76.62 \%$; step 5 (supporting mothers to start and maintain breastfeeding) an average of $82.27 \%$; step 6 (exclusive breastfeeding) an average of $81.39 \%$; step 7 (joint accommodation) an average of $98.04 \%$; step 8 (recognition of the baby's signs of hunger) an average of 86.39; step 9 (avoid the use of suckers and bottles) an average of $96.46 \%$; and step 10 (breastfeeding support groups) an average of $74.89 \%$.

\section{Discussion}

In this work, we describe the results of the follow-up to 2 General Zone Hospitals in the state of Puebla. We evaluated the ten steps to identify areas for improving breastfeeding practices and support infant feeding, as mentioned by the WHO. Follow-ups in countries such as Brazil, the United States (North Carolina, New York and lowa), Pakistan, and Canada reported that the percentages range from $75 \%$ to $100 \%$, in this study the percentages ranged from 70 to $100 \%$.

The hospitals evaluated reported an overall average of $88.83 \%$ for General Zone Hospital No. 5 and $84.74 \%$ for General Zone Hospital No. 15; the numbers remained around the same range considering that General Zone Hospital No. 5 has only 4 follow-ups and General Zone Hospital No. 15 has 7.

While we compared scores between our results and those of other hospitals in different countries, we only found one study ${ }^{15}$ which reported the scores of both the steps and the annexes. However, we found pertinent to report our findings in table 3 regarding the results of the annexes in our study.

The follow-ups assessed the attachment of hospitals to the guidelines described by the WHO and UNICEF, to identify the most difficult steps to implement to be able to propose some solution to these obstacles.

The step with the highest percentage of non-compliance was that related to the immediate attachment of newborns with their mother, we will reinforce in the follow-up the benefits of skin-to-skin contact performed immediately for at least $1 \mathrm{~h}$, which has been investigated and reported in numerous studies ${ }^{16}$, with effects on
Table 2. Comparison of the scores of General Zone Hospital No. 5 and No. 15 of follow-ups in breastfeeding

\begin{tabular}{|c|c|c|c|c|}
\hline & Hospital & $\begin{array}{l}n \text { (number } \\
\text { of traces) }\end{array}$ & Media $\pm D . S$ & Value (p) \\
\hline \multirow[t]{2}{*}{ Step 1} & 5 & 4 & \pm 100.0 & 0.010 \\
\hline & 15 & 7 & $87 \pm 14$ & \\
\hline \multirow[t]{2}{*}{ Step 2} & 5 & 4 & \pm 100.0 & 0.057 \\
\hline & 15 & 7 & $74 \pm 13$ & \\
\hline \multirow[t]{2}{*}{ Step 3} & 5 & 4 & $93 \pm 2$ & 0.176 \\
\hline & 15 & 7 & $88 \pm 16$ & \\
\hline \multirow[t]{2}{*}{ Step 4} & 5 & 4 & $78 \pm 8$ & 0.949 \\
\hline & 15 & 7 & $75 \pm 9$ & \\
\hline \multirow[t]{2}{*}{ Step 5} & 5 & 4 & $81 \pm 11$ & 0.657 \\
\hline & 15 & 7 & $82 \pm 10$ & \\
\hline \multirow[t]{2}{*}{ Step 6} & 5 & 4 & $78 \pm 16$ & 0.754 \\
\hline & 15 & 7 & $83 \pm 17$ & \\
\hline \multirow[t]{2}{*}{ Step 7} & 5 & 4 & $95 \pm 3$ & 0.023 \\
\hline & 15 & 7 & $99 \pm 1$ & \\
\hline \multirow[t]{2}{*}{ Step 8} & 5 & 4 & $89 \pm 2$ & 0.105 \\
\hline & 15 & 7 & $85 \pm 7$ & \\
\hline \multirow[t]{2}{*}{ Step 9} & 5 & 4 & $98 \pm 2$ & 0.091 \\
\hline & 15 & 7 & $95 \pm 7$ & \\
\hline \multirow{2}{*}{$\begin{array}{l}\text { Step } \\
10\end{array}$} & 5 & 4 & $74 \pm 9$ & 0.468 \\
\hline & 15 & 7 & $75 \pm 19$ & \\
\hline
\end{tabular}

the optimal thermoregulation of the baby ${ }^{17}$, on the serum glucose levels of the newborn ${ }^{18}$, the decrease of birth stress on the psychological well-being of the newborn, ${ }^{19,20}$ and an improvement in cardiopulmonary dynamics ${ }^{20}$.

Likewise, the factors that interfere with being able to carry out skin-to-skin contact immediately have been identified, these mainly represent the lack of knowledge of the clinical staff about the benefits of this practice, the insecurity of the parents to support the newborn, and the lack of an algorithm established to choose newborns who may or may not perform this practice $^{21}$.

Another step with insufficient percentage is the one related to support groups for breastfeeding; these groups are destined to maintain breastfeeding for as long as necessary and to solve all doubts and concerns that may worry the mothers. A study made in the 
Table 3. Registry of the scores obtained for the annexes in both hospitals, expressed in percentages

\begin{tabular}{|c|c|c|c|c|c|c|c|c|c|c|}
\hline & \multicolumn{4}{|c|}{ General Zone Hospital 5} & \multicolumn{5}{|c|}{ General Zone Hospital 15} & \multirow{2}{*}{$\begin{array}{c}\begin{array}{c}\text { Ghana } \\
\text { Hospital }\end{array} \\
\text { May-15 }\end{array}$} \\
\hline & September-15 & Febuary-16 & August-16 & March-17 & March-15 & September-15 & March-16 & September-16 & March-17 & \\
\hline $\begin{array}{l}\text { Annex } \\
1\end{array}$ & 93.1 & 96 & 100 & 100 & 100 & 83.3 & 100 & 100 & 80 & 85.8 \\
\hline $\begin{array}{l}\text { Annex } \\
2\end{array}$ & 74.07 & 93 & 83.3 & 86.6 & 66.6 & 74 & 57 & 76.6 & 60 & 34 \\
\hline $\begin{array}{l}\text { Annex } \\
3\end{array}$ & 89.6 & 88 & 86.6 & 76.6 & 91.6 & 82.5 & 91 & 88.3 & 93.3 & 47 \\
\hline
\end{tabular}

Netherlands registered $66 \%$ more compliance with breastfeeding within women who had a support group ${ }^{22}$.

For a support group to function ideally and thus lengthen the time that mothers provide breastfeeding to their babies, several characteristics are needed, that the support group is aimed at a specific group of women, that the place where the meetings are held is accessible and comfortable and that there is advertising of the same so that all pregnant mothers and mothers are aware that it exists ${ }^{23}$.

A compendium of five qualitative studies found that the support of health professionals has a major influence on women's experiences with breastfeeding practice, but that the current promotion of the initiative promotes unrealistic expectations of what breastfeeding should look like?

\section{Limitations of the study}

The follow-up was only carried out only in two Hospitals of the State of Puebla, of which the General Zone Hospital No. 5 did not continue its follow-up due to the earthquake that happened on September 19 2017, which left the hospital disabled even to this day, which made its follow-up insufficient, so the findings found in this study may not be widespread to other populations.

\section{Conclusion}

In the follow-up steps 2, 4, 7, and 8, the Baby Friendly Initiative had oscillating scores over time, step 4 had the lowest scores, so the promotion of obstetric practices, especially skin to skin contact, a simple, easy-to-execute, inexpensive method, requires an adequate training of health personnel for its realization which will have a positive effect on both the binomial and the baby's development.

\section{Funding}

There was no funding from any organization for this article.

\section{Conflicts of interest}

There were no conflicts of interest from any of the authors involved.

\section{Ethical disclosures}

Protection of human and animal subjects. The authors declare that no experiments were performed on humans or animals for this study.

Confidentiality of data. The authors declare that they have followed the protocols of their work center on the publication of patient data.

Right to privacy and informed consent. The authors have obtained the informed consent of the patients and/or subjects referred to in the article.

\section{References}

1. World Health Organization. Implementation Guidance: protecting, Promoting and Supporting Breastfeeding in Facilities Providing Maternity and Newborn Services the Revised Baby-friendly Hospital Initiative. Geneva: World Health Organization; 2018. p. 56

2. Lamounier JA, Chaves RG, Rego MA, Bouzada MC. Baby friendly hospital initiative: 25 years of experience in Brazil. Rev Paul Pediatr. 2019; 37:486-93.

3. de Fátima Moura de Araújo M, de Abreu Soares Schmitz B. Reassessment of baby-friendly Hospitals in Brazil. J Hum Lact. 2007:23:246-52.

4. Chehab MA, Selim NA, Itani R. The baby-friendly hospital initiative and Qatar, 2016. J Taibah Univ Med Sci. 2018;13:309-10.

5. Labbok MH. Global baby-friendly hospital initiative monitoring data: update and discussion. Breastfeed Med. 2012;7:210-22.

6. World Health Organizations. The World Health Organization's Infant Feeding Recommendation. The World Health Organization's Infant Feeding Recommendation. Geneva: World Health Organizations; 2015. 
7. Fallon VM, Harrold JA, Chisholm A. The impact of the UK Baby Friendly Initiative on maternal and infant health outcomes: a mixed-methods systematic review. Matern Child Nutr. 2019;1:1-22.

8. Kent G. Child feeding and human rights. Int Breastfeed J. 2006:1:1-12

9. Lillehoj CJ, Dobson BL. Implementation of the baby-friendly hospital initiative steps in iowa hospitals. J Obstet Gynecol Neonatal Nurs. 2012;41:717-27.

10. Taylor EC, Nickel NC, Labbok MH. Implementing the ten steps for successful in hospitals serving low-wealth patients. Am J Public Health 2012:102:2262-8

11. Hawke BA, Dennison BA, Hisgen S. Improving hospital breastfeeding policies in New York state: development of the model hospital breastfeeding policy. Breastfeed Med. 2012;8:3-7.

12. Masood S, ur-Rahman M, Mahmood H, Faisal T, Maroof S, Qureshi AM. Observance of who ten steps towards successful breastfeeding; a survey from postpartum mothers. J Ayub Med Coll Abbottabad. 2016:28:84-8.

13. Haiek LN. Compliance with baby-friendly policies and practices in hospitals and community health centers in Quebec. J Hum Lact. 2012;28:343-58.

14. World Health Organization. The Hospital Friend of the Child Initiative, Revised, Updated and Expanded for Comprehensive Care. Vol. 4. Geneva: World Health Organization; 2009. p. 1-104.

15. Agbozo F, Ocansey D, Atitto $P$, Jahn A. Compliance of a baby-friendly designated hospital in ghana with the WHO/UNICEF baby and mother-friendly care practices. J Hum Lact. 2020;36:175-86.

16. Cadwell K, Phillips R, Brimdyr K. Mapping, measuring, and analyzing the process of skin-to-skin contact and early breastfeeding in the first hour after birth. Breastfeed Med. 2018;13:485-92.
17. Beiranvand $S$, Valizadeh F, Hosseinabadi R, Pournial $Y$. The effects of skin-to-skin contact on temperature and breastfeeding successfulness in full-term newborns after cesarean delivery. Int J Pediatr. 2014;2014: 846486.

18. Moore ER, Bergman N, Anderson GC, Medley N. Early skin-to-skin contact formothers and their newborn healthy infants. Cochrane Database Syst Rev. 2016;11:CD003519.

19. Bystrova K, Widstrom AM, Matthiesen AS, Ransjö-Arvidson AB, Welles-Nyström B, Wassberg $\mathrm{C}$, et al. Skin-to-skin contact may reduce negative consequences of "the stress of being born": a study on temperature in newborn infants, subjected to different ward routines in St. Petersburg. Paediatr Int J Paediatr Act. 2003;92:320-6.

20. Takahashi $\mathrm{Y}$, Tamakoshi K, Matsushima M, Kawabe T. Comparison of salivary cortisol, heart rate, and oxygen saturation between early skinto-skin contact with different initiation and duration times in healthy, fuII-term infants. Early Hum Dev. 2011;87:151-7.

21. Koopman I, Callaghan-Koru JA, Alaofin O, Argani CH, Farzin A. Early skin-to-skin contact for healthy full-term infants after vaginal and caesarean delivery: a qualitative study on clinician perspectives. J Clin Nurs. 2016;25:1367-76.

22. van Dellen SA, Wisse B, Mobach MP, Dijkstra A. The effect of a breastfeeding support programme on breastfeeding duration and exclusivity: a quasi-experiment. BMC Public Health. 2019;19:993.

23. Green K. 10 must-two for breastfeeding successful support groups. Breastfeed Med. 2012;7:346-7. 